\title{
How Effectively Can Students' Personal Smartphones be Used as Tools in Physics Labs?
}

\author{
https://doi.org/10.3991/ijim.v15i14.22375 \\ Serafeim Tsoukos \\ $2^{\text {nd }}$ Experimental Junior High School, Athens, Greece \\ Panagiotis Lazos \\ National and Kapodistrian University, Athens, Greece \\ $4^{\text {th }}$ Laboratory Center of Natural Sciences, Athens, Greece \\ Pavlos Tzamalis \\ Agricultural University, Athens, Greece \\ Alexandros Kateris \\ $2^{\text {nd }}$ Experimental Lyceum, Athens, Greece \\ Athanasios Velentzas $(\square)$ \\ National Technical University, Athens, Greece \\ avelentz@gmail.com
}

\begin{abstract}
This study seeks to answer the question of how effectively students can use their smartphones as tools for measuring and processing data when they perform physics experiments. The research was conducted in a local secondary school in Athens, Greece. The sample consisted of fifty-two 16-yearold students (10th grade), who were divided into 26 pairs and asked to perform an experiment using their smartphones for measuring, processing and saving data, and then to email the data file to the researchers. During the implementation, each pair completed the steps on a worksheet. Two researchers monitored each pair individually, and recorded scores and comments on evaluation sheets. The worksheets, the evaluation sheets, and the experimental data emailed by each pair constituted the data of the present study. The findings of the study show that the integration of students' smart mobile devices in the performance of physics experiments in the classroom or in the school lab is possible without posing particular problems. However, this integration presupposes the proper planning by the teacher and the dedication of appropriate time both for the preparation of students for the activity, and for the installation of the necessary applications in the devices.
\end{abstract}

Keywords - Smartphone Sensors; School Lab; BYOD; Physics Experiments 


\section{Introduction}

The fact that as early as 2014 in some of the most developed Western countries, such as the United States, Germany, the United Kingdom and Japan, the number of smartphones exceeded the number of desktop PC's [1] vividly shows the degree of penetration of these types of devices in our everyday lives. It is reasonable to assume that since 2014, many more countries have been added to this group. The continuous reduction in the cost of this kind of technology convinces us that sooner or later in most countries smartphones will be used by almost everyone. Combining this development with the fact that mobile devices are widespread especially among younger people, the transition from the field of education that is usually called "electronic learning", or "e-learning", to the new era of "mobile learning" or "m-learning", becomes inevitable [2]. The assumption that such a transition is actually taking place is also documented by the increase in the number of articles in the field of m-learning worldwide. For example, Hwang and Tsai [3] found that the number of papers published in the field of m-learning from 2005 to 2010 was four times higher than the corresponding number for the years 2001 to 2005, and this increase continues [4].

Although there is an intense and evolving debate in the international literature both on the definition of m-learning [5] and on the devices and applications that can be included in this category of education [6] [7] [8], in the present work we will adhere to the minimum common position that has been shaped by these discussions: Thus, there gradually seems to be an increasing agreement among different researchers that the field of m-learning includes devices which can be easily transported, due to their small size and weight, while having the capability of wireless connection with the World Wide Web (WWW). Typical devices that meet such criteria are mobile phones (MPs) and tablets.

Several papers show that, despite some problems, such as distraction or small keyboards [9], learning is aided by mobile phones, as long as appropriate rules have been posed [10]. In addition to the general advantages of m-learning identified by different researchers [11], such as learning without local and temporal limitations, connectivity with the WWW, ease of data exchange in different formats such as images, videos, texts, and so on, m-learning devices also have an additional advantage as far as science education in general is concerned [4] [12], and especially in physics courses [13] [14] and in the physics laboratory classes [15]. More specifically, we are referring to the exploitation of the capabilities provided by the various built-in sensors that all these mobile devices have, which are used to serve some of their basic functions. For example, the acceleration sensor is used to change the orientation of the screen every time a smartphone is rotated. Using appropriate applications, data can be extracted from these sensors, which data can be immediately visualized with graphs on the mobile device and often processed in order to obtain some preliminary results. The multiplicity of the sensors in the modern MPs, such as light and sound sensor, gyroscope, magnetic sensor, and others, allow the conducting of experiments in different areas of physics, e.g. mechanics [16] [17], optics and acoustics [18] [19], heat and thermodynamics [20], and even in modern physics [21]. In addition, the easy, wireless and seamless connectivity of these devices to the WWW can help teachers share the 
data with their students, create teams of students working collaboratively, and in general interact directly with them. The review of the relevant literature [15] highlights both the variety of the use of MPs and tablets in the school, and the development of the educational research in the corresponding field: Thus, the integration of $\mathrm{m}$ learning into the educational process and the training of teachers in this field are now considered necessary [22]. This specific use of mobile devices and the possibilities it offers to students for conducting experiments when they do not have access to the appropriate laboratory equipment seems to have been a solution that many teachers resorted to during the recent COVID-19 pandemic [23].

However, in order to advance learning through the use of mobile devices, one of the first and most basic problems that needs to be resolved is how to integrate mlearning into education [1] in general, and into the science school lab in particular. Among the different proposals that have been put forward, one is summarised with the phrase "Bring Your Own Devices" (BYOD). It is a strategy that initially started in the business sector and was then extended to other areas, including education [24] [25]. It is worth remembering that an alternative idea, namely providing inexpensive personal computers to students in developing countries, was proposed by N. Negroponte in 2000, and began to be implemented in 2005 (http://one.laptop.org/). The BYOD proposal has significant advantages for an educational system, including the fact that students are already familiar with the use of their own devices, and that schools are not financially burdened by the purchase of specialized laboratory devices that usually come at a high price, although there are still other open problems with BYOD that need to be overcome [26] [27]. On the other hand, of course, it is expected that the plethora of all these different devices that students bring to the classroom, and which the teacher must coordinate during a laboratory course, may pose significant problems, an issue that was examined by Kateris et al. [28]. The specific way in which students' mobile devices students are integrated into teaching must therefore be studied in real-world conditions to detect any problems that may arise.

In this paper, we focus our attention on the practicality for taking measurements using the MP sensors of the devices that students bring to the laboratory. The problems that are expected to arise may be due, on the one hand, to the differences between students' devices attributable to different manufacturers, models, and software and, on the other hand, to the ability of students to use the devices and the necessary software when implementing the instructions of a worksheet. As far as regards the first type of problems, i.e., problems due to device differences, previous research [28] has shown that the teacher who implements the BYOD model will not encounter particularly significant problems due to the plethora of students' different mobile devices. As for the second kind of problems, i.e., student's ability to correctly use the devices for measurement, there are no surveys focusing on the ability of students to use the devices in a demanding sequence of experimental procedures in the context of a physics laboratory. What is unique in this study is an attempt to provide information on this issue.

There have been surveys focusing on students' working cooperatively and the enhancement of their interest/ motivation [29] [30], reports of potential benefits from the use of MPs in teaching and learning [31], as well as many suggestions for educational 
exploitation of the sensors of a MP for the presentation of physics experiments (e.g. [16] [19] [32] [33]). The present study was designed to identify the technical difficulties that students would encounter when conducting an experiment using their own MPs in the school lab. A controlled environment was therefore chosen, where two pairs of students successively performed the same experiment (about which they had previously been instructed) in front of two of the researchers. The researchers monitored each pair's performance, and assessed them as they were carrying out the various steps to successfully complete the experiment. Thus, the main question that the present research is trying to answer is "To what degree are students able to use their MPs to take measurements and process data in the school science laboratory when following the instructions on a worksheet?"

\section{Materials and Methods}

\subsection{The selection of the experiment}

The selected experiment concerned the measurement of the acceleration of a body (a rectangular wooden parallelepiped) sliding on an inclined plane (the surface of a desk), and the calculation of the coefficient of kinetic friction between the two surfaces. One end of the desk was raised, creating an inclined plane of inclination angle $\varphi$. Then, students attached their MP on the rectangular wooden parallelepiped and the resultant body (parallelepiped + MP) was allowed to slide from the top to the bottom of the inclined plane. The measurement of the acceleration $(a)$, as well as the value of the angle $\varphi$, was accomplished using the accelerometer of the smartphone. The coefficient of kinetic friction can be calculated from the formula:

$$
\mu=\frac{g \cdot \sin \varphi-\alpha}{g \cdot \cos \varphi}
$$

This specific experiment was selected because it had been tested in a relevant study and it was found that the measured values, from a variety of devices, did not have statistically significant differences [28]. Another criterion for selecting this particular experiment was the fact that not only did the participating students have to make a simple measurement, they also had to follow instructions for a variety of procedures. The specific procedures and steps are described in detail in the section "The Sample and Preparation" but in brief, students were required to install multiple applications on their MPs, learn how to handle them, obtain measurements of the angle of inclination and acceleration, adjust the settings on their MPs according to the specific task, record, save, and send data in a specific format, and perform appropriate calculations.

\subsection{The worksheet and the pilot implementation}

To ensure better observation of students' performance and obtain a more detailed evaluation of possible technical difficulties they might encounter, it was decided that the experiment should be performed by as small groups of students as possible, i.e., 
by two students working in a pair. Then, a worksheet with nine steps was created, as described below in the "Findings-Results" section. The worksheet was tested with three groups of students to check for possible problems, mainly relating to the students' understanding of the given instructions. After the identification of some ambiguities and some points difficult for students to understand, improvements were made, and the final form of the worksheet was prepared. One of the findings of the pilot research that is worth noting was the problem students had in interpreting the acceleration time diagram. In particular, they faced great difficulty in recognizing the area of the graph on the MP screen where the body was sliding across the inclined plane with constant acceleration. This difficulty may be attributable to the fact that the graph of the actual experiment differs significantly from the theoretical graphs that the students are familiar with. This problem was taken into consideration during the actual implementation, as mentioned below in the section "Implementation and Evaluation".

\subsection{The sample and the preparation}

The sample consisted of fifty-two 16-year-old 10th grade physics students attending a secondary school in Athens, who were organized into 26 pairs. It is important to note that all students were informed about the whole procedure before the implementation of the experiment during a one-hour briefing session.

Specifically, during the briefing session, the students:

- Downloaded and installed the necessary apps on their MPs: "Bubble level" (Gamma Play/Android - Lemondo entertainment/iOS) and the "Sparkvue" (Pasco) app for all operating systems.

- Became familiar with the "Bubble level" app so that they could measure the angle of the inclined plane.

- Became familiar with the "Sparkvue" app so that they would be able to complete the relevant steps in the experiment.

- Became familiar with the calculator app of their MP so that they could calculate the sine and cosine of an angle.

\subsection{Implementation and evaluation}

Each pair of students performed the experiment "individually" (i.e., one pair in the lab at a time) so that the researchers could record their performance and any possible difficulties in detail. A worksheet with written instructions was given to each pair, and they had to follow the steps to complete the experiment. Each pair used an MP belonging to one of them, in which the necessary apps had been installed during the preimplementation briefing. The performance of the experiment required the participation of at least two students, without it being possible for both of them to perform all the operations on the MP at the same time. For example, one of the students released the body from the top of the inclined plane, and the other had to catch it at the end of its track. However, they were permitted to discuss how to adjust the settings on the MP and how to process the data. Therefore, the evaluation focused on the collabora- 
tive result of the pair, and not on each of them individually, although observations about cooperation and individual difficulties were recorded. It should be noted that in the reality of the classroom or the laboratory, the experiments are performed by students working in pairs or larger groups.

In order to achieve a more objective and transparent evaluation, two researchers, each having a preliminary evaluation sheet, simultaneously monitored the successive pairs of the students performing the experiment and recorded scores and comments. These preliminary evaluation sheets contained the same steps as did the students' worksheets. When each pair of students had completed the experiment and left the lab, the researchers compared their preliminary evaluations, discussing their comments and their points of agreement or disagreement in order to arrive at a final evaluation, which was recorded on a separate sheet. The students' worksheets, the final evaluation sheets, and the data emailed by each pair of students to the researchers constituted the data of this research.

The present study explores the students' ability to use their MPs for performing experiments in the school lab and does not focus on conceptual difficulties. For example, as had also been the case during the pilot implementation, students had difficulty interpreting the acceleration time diagram. To overcome this, the researchers intervened and provided the necessary explanations. Concerning the students' ability to use the devices to follow the instructions on the worksheet, the researchers assessed students' performance on the evaluation sheet based on a scale from 1 to 4 , as well as by making notes or comments about their observations. The assessment score of 1 corresponds to the cases where students were for some reason unable to perform the step by themselves, and the intervention of the researchers was necessary in order for the pair of students to proceed to the next step. The score of 4 corresponds to the cases in which the students effectively and efficiently performed the experiment entirely on their own. The scores of 2 and 3 refer to cases where students required some degree of help or a reminder. Specifically, the following ten key points of the experiment were assessed:

1. Measurement of the angle of the inclined plane

2. Starting a new experiment

3. Setting of the measurement rate

4. Setting the precision of the measurements

5. Zeroing out the initial acceleration

6. Starting data recording

7. Storing/saving of data

8. Calculating the average value of the acceleration

9. Storing/saving of the changes to the graph

10. Using of the MP's calculator

These points were incorporated into a series of nine numbered procedural steps on the students' worksheets, steps which are described in the "Findings-Results" section below.

It is worth noting that a meta-analysis of both the completed student worksheets (i.e., a check of students' calculations) and the files of the "Sparkvue" app emailed by 
the students were taken into consideration for the final evaluation. For example, the students had been asked to zero out the acceleration sensor when the body was placed on the inclined plane. The meta-analysis of the data, and particularly the review of the acceleration time graph, clearly showed whether (i) the students had correctly set the acceleration to zero with the body on the inclined plane, or (ii) they had not done it at all, or (iii) they had incorrectly done it with the MP on the horizontal plane (table). Also, from the same graph, we were able to identify whether the students had chosen the correct "Range of Interest" in order to calculate the average value of the acceleration.

\section{$3 \quad$ Findings-Results}

The following are the findings for each step of the experiment procedure included on the worksheet. An analysis of the scores is shown in Table 1.

Table 1. Scores of selected worksheet steps

\begin{tabular}{|c|c|c|c|c|}
\hline & $\begin{array}{c}\% \text { of } \\
\text { pairs rated } 1\end{array}$ & $\begin{array}{c}\% \text { of } \\
\text { pairs rated } 2\end{array}$ & $\begin{array}{c}\% \text { of } \\
\text { pairs rated } 3\end{array}$ & $\begin{array}{c}\% \text { of } \\
\text { pairs rated } 4\end{array}$ \\
\hline $\begin{array}{l}\text { Step 3: } \\
\text { Calculation of angle } \varphi\end{array}$ & $0 \%$ & $0 \%$ & $15 \%$ & $85 \%$ \\
\hline \multicolumn{5}{|l|}{ Step 4: } \\
\hline \begin{tabular}{|l|} 
Sub-step 4.1: \\
Start a new experiment \\
\end{tabular} & $8 \%$ & $8 \%$ & $8 \%$ & $76 \%$ \\
\hline $\begin{array}{l}\text { Sub-step 4.2: } \\
\text { Set measurement rate to } 1 \mathrm{kHz}\end{array}$ & $8 \%$ & $4 \%$ & $4 \%$ & $85 \%$ \\
\hline $\begin{array}{l}\text { Sub-step 4.3: } \\
\text { Precision } 0.01 \mathrm{~m} / \mathrm{s}^{2} \\
\end{array}$ & $4 \%$ & $15 \%$ & $23 \%$ & $58 \%$ \\
\hline $\begin{array}{l}\text { Sub-step 4.4: } \\
\text { Zero out the sensor }\end{array}$ & $15 \%$ & $4 \%$ & $8 \%$ & $73 \%$ \\
\hline $\begin{array}{l}\text { Sub-step 4.5: } \\
\text { Start Recording }\end{array}$ & $4 \%$ & $12 \%$ & $15 \%$ & $69 \%$ \\
\hline \begin{tabular}{|l|} 
Step 5: \\
Data storage \\
\end{tabular} & $4 \%$ & $0 \%$ & $4 \%$ & $92 \%$ \\
\hline \begin{tabular}{|l|} 
Step 7: \\
Find the mean acceleration value \\
\end{tabular} & $12 \%$ & $15 \%$ & $38 \%$ & $35 \%$ \\
\hline $\begin{array}{l}\text { Step 8: } \\
\text { Save changes }\end{array}$ & $0 \%$ & $0 \%$ & $0 \%$ & $100 \%$ \\
\hline $\begin{array}{l}\text { Step 9: } \\
\text { Calculations }\end{array}$ & $0 \%$ & $4 \%$ & $23 \%$ & $73 \%$ \\
\hline
\end{tabular}

\subsection{Steps 1 and 2: Preparation}

As mentioned above, the appropriate applications had been downloaded to the students' MPs during the pre-implementation briefing. In steps 1 and 2, each pair of students initially had to decide which of their two MPs they would use, and then mount it onto the wooden parallelepiped, provided by the researchers, to create the body that would slide down the inclined plane. The procedures involved in these steps 
do not concern the major questions of our survey, and therefore no grades were assigned, or corresponding findings recorded.

\subsection{Step 3: Measurement of angle $\varphi$}

Students first had to launch the "Bubble Level" application on their MPs and place the body they had created in Steps 1 and 2 at the top of the inclined plane (Figure 1). Then, they had to hold it steady in order to find the angle of inclination $\varphi$, using the above-mentioned application which measures the inclination of the screen level of the MP relative to the horizontal plane (Figure 2). When the body is placed on the inclined plane, with the $y$ axis across the inclined plane, then the angle of inclination of the $y$ axis of the MP is the one to be recorded, while the angle of inclination of the $x$ axis is almost zero. The angle of inclination of each axis is shown as a positive or negative value by the "Bubble Level" app, depending on the orientation of the MP relative to the plane. Clearly, the absolute value must be recorded in the worksheets. All the above points had been explained to the students during the pre-implementation briefing.

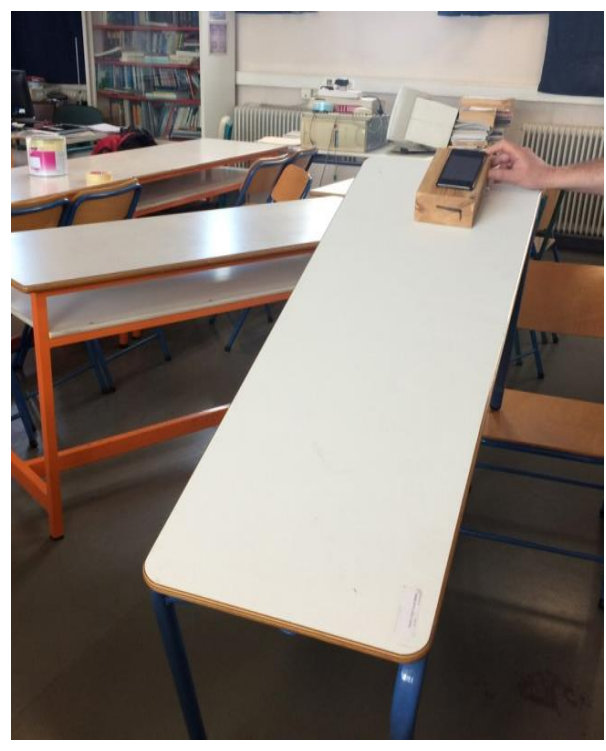

Fig. 1. The experimental setup

Findings: Twenty-two of the twenty-six student pairs $(85 \%)$ received a grade of 4 , and the remaining four pairs a grade of 3. Students who received a grade of 3 had some difficulty completing the worksheet on their own and had resorted to asking the researchers for help in choosing the appropriate angle of inclination or recording the negative sign of the angle of inclination.

It is worth mentioning that one pair of students thought that the height at which the MP is placed plays a role in measuring the angle of inclination of the plane, and that 
the appropriate position for determining the measurement is at the lowest point of the inclined level (i.e., it's base). This finding, along with others presented below, demonstrates some conceptual difficulties that students face and which need further investigation, but are not the subject of this research.
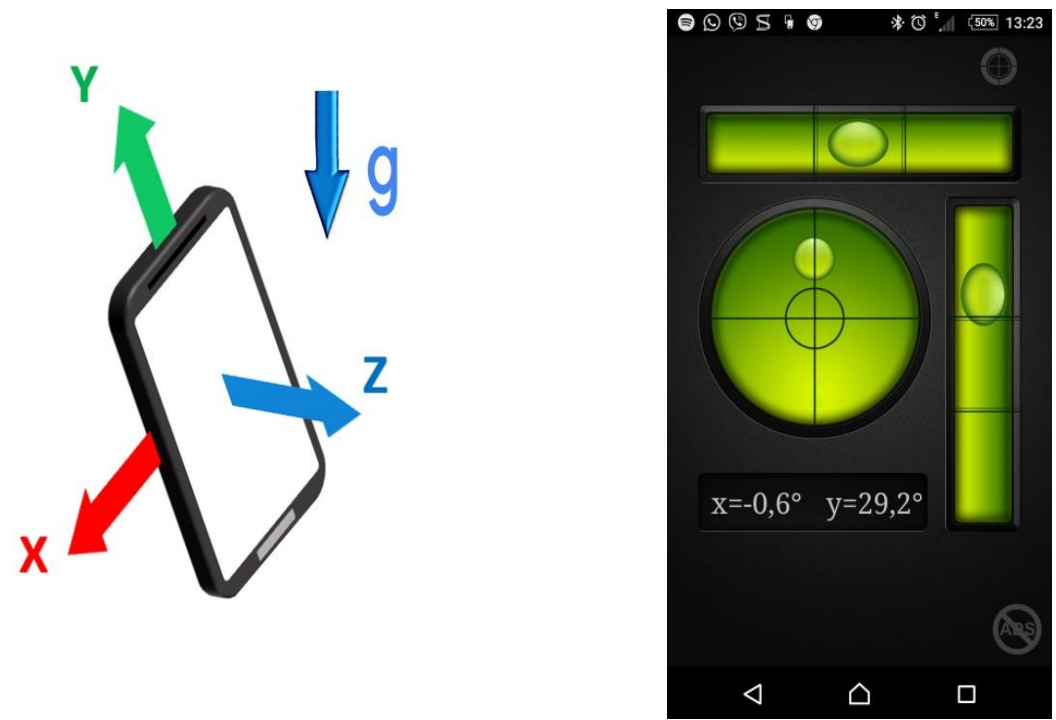

Fig. 2. Left, the MP's $x, y$ and $z$ axes. Right, the inclination angles of the MP's $x$ and y axes as measured with the "Bubble level" app

\subsection{Step 4}

In this crucial step, students were asked to complete tasks by using certain options of the "Sparkvue" app, which required their following a procedure with five substeps:

Sub-step 4.1: Start a new experiment: In this sub-step, students were asked to start a new experiment to record the total (net) acceleration with a graph, using the "Sparkvue" application. This application enables the recording of the acceleration in each of the three axes ( $\mathrm{x}, \mathrm{y}$, and $\mathrm{z}$ ), as well as the total acceleration of the body as a function of time.

Findings: A few pairs of students did not remember the procedure which had been presented to them earlier during the pre-implementation briefing, requiring an intervention from the researchers in order for them to proceed with the execution of the experiment. Specifically, $8 \%$ of the pairs received a grade of 1 (i.e., they required critical help), $8 \%$ received a grade of 2 (i.e., a reminder/ some help required), $8 \%$ received a grade of 3 (i.e., simple confirmation of students' questions), and finally $76 \%$ of the pairs received a grade of 4 (i.e., no help required).

Sub-step 4.2: Set measurement rate to $1 \mathrm{kHz}$ : For the purposes of this sub-step of the experiment, students had to set the measurement rate on the "Sparkvue" application equal to $1 \mathrm{kHz}$. 
Findings: It is worth noting that the pairs that had difficulties in sub-step 4.2 also encountered difficulties in step 4.1, leading to similar scores. Specifically, $84 \%$ of the pairs received a grade of $4,4 \%$ received a grade of $3,4 \%$ a grade of 2 , and finally $8 \%$ of the pairs a grade of 1 .

Sub-Step 4.3: Set the precision of net acceleration to $0.01 \mathrm{~m} / \mathrm{s} 2$ : Students had to use the "Sparkvue" application to set the precision of acceleration to two decimal places.

Findings: Fifteen student pairs $(58 \%)$ received a grade of 4 , while six pairs $(23 \%)$ received a grade of 3 . The latter grade was assigned because three of the six pairs had initially inadvertently skipped this sub-step, but were able to do it without help when the researcher pointed out their omission, while the other three pairs asked for confirmation to perform the task. Five pairs (19\%) had difficulty realizing that the required precision in the measurement of acceleration is achieved by setting the number of decimal places to 2 , even though this procedure had been demonstrated and practiced during the pre-implementation briefing. Of these five pairs, four received a grade of 2 (i.e., a reminder was needed), and one pair received a grade of 1 (i.e., the setting on the "Sparkvue" application had to be adjusted by the researcher).

Sub-step 4.4: Zeroing out the acceleration sensor: In this sub-step, the students were asked to "zero out", i.e. reset, the acceleration sensor when the body was at rest. If there is no zeroing out, the sensor also measures the acceleration of gravity.

Findings: The crucial point during the execution of this sub-step was for students to zero out the acceleration sensor after the body had been placed on the inclined plane and was kept at rest, a requirement which had been pointed out to students during the pre-implementation briefing. One pair of students $(4 \%)$ did not zero out and were helped by the researchers (graded with a 2), while two pairs $(8 \%)$ of students asked for confirmation that they had to zero out when the body was on the inclined plane (graded with a 3). The processing of the student graphs sent to the researchers showed that $15 \%$ of the groups had zeroed out when the body was on a horizontal plane (table) and continued the process, resulting in a systematic error in measuring the mean value of acceleration (graded with a 1 ). The remaining $73 \%$ of the pairs received the grade of 4 .

Sub-step 4.5: Start recording: Students were asked to first start recording the acceleration readings using the option provided by the application, and then to release the body in order to move freely on the inclined plane.

Findings: During the experiment, three pairs of students $(12 \%)$ did not remember to start the recording, and were helped by the researchers (receiving a grade of 2), four pairs of students $(15 \%)$ asked for confirmation that they should start the recording (graded with a 3), while the students in one pair let the body move without starting the recording and, after the end of the descent of the body, they realized that the acceleration values had not been recorded (graded with a 1), and were allowed to repeat the experiment. The remaining 18 pairs $(69 \%)$ received the grade of 4 . 


\subsection{Step 5: Storage of data}

In this step, the students were asked to save the measurements as well as the graph of the total (net) acceleration over time in a new file. The "Sparkvue" application uses a specific file format with the extension ".spklab".

Findings: This step was designed so as to provide the researchers with a complete picture of all the data students had obtained during the experimental process in order to evaluate them. During the experiment, one pair of students asked if they had to save the data, receiving a positive answer from the researchers (graded with 3), while one pair ignored the step (receiving a grade of 1 ) and subsequently repeated the experiment. The remaining 24 pairs of students $(92 \%)$ saved the data as specified in the worksheet and received a grade of 4 .

\subsection{Step 6: Analysis of the acceleration graph}

Students were asked to study the graph of acceleration as a function of time (Figure 3) and to determine not only the area of the graph indicating where the body slid down the inclined plane, but also the area where the body was immobilized (by the student at the base of the plane).

Findings: As previously mentioned, in "The Worksheet and the Pilot Implementation" section, the students had significant difficulty in interpreting the graph, a situation which was also evident during the actual implementation. However, since the purpose of this study is to investigate the ability of students to use their MPs to complete all the steps in the process of an experiment by following the instructions in a worksheet, a goal that does not require students to understand the concepts involved, the researchers intervened in this step and explained the form of the diagram to the students. As already mentioned in the section "The Implementation and the Evaluation", this step was not graded (and therefore is not included in Table 1), but nevertheless gives rise to the reflection that will be developed in the section "Discussion and Conclusions".

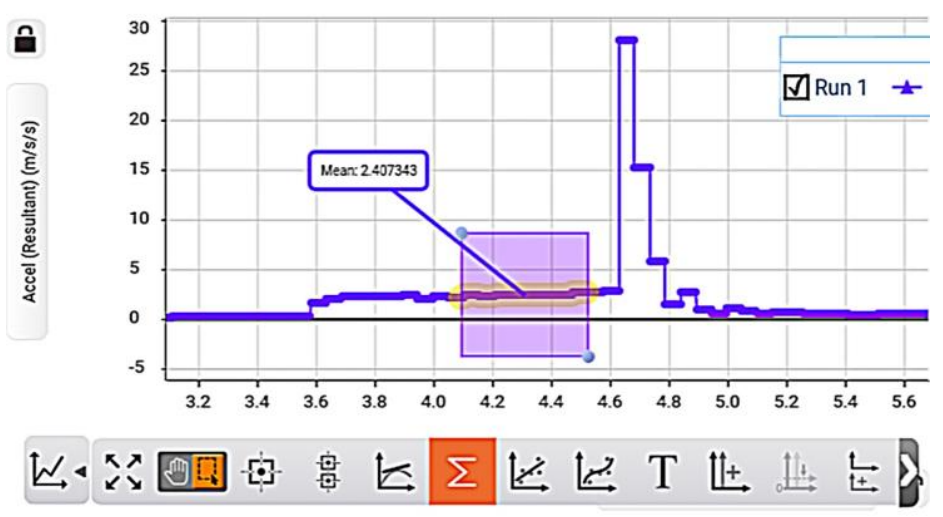

Fig. 3. Calculation of the average value of the acceleration with the "Sparkvue" application 


\subsection{Step 7: Finding the mean acceleration value}

Students had to choose an appropriate scale and focus (zoom) on the graph on their MP screens properly so that the area showing the movement of the body on the inclined plane was clearly visible at the point where a constant acceleration (plateau area) was expected to occur. They then had to draw (by sliding their fingers on the screen) an appropriate rectangular area (ROI-range of interest) which would include the whole of the plateau or a sufficient part of it (Figure 3). Finally, using the appropriate tools of the application, the average value of acceleration in the chosen area would be calculated automatically, and this value had to be recorded.

Findings: As mentioned above in the "the Implementation and the Evaluation" section, the researchers conducted a meta-analysis of all the graphs submitted by the 26 student pairs after the experiment, at which time they assigned a final evaluation score to step 7, taking into consideration the students' conclusions and choices. Nine pairs (35\%) completed the step well and received a grade of 4 , ten pairs (38\%) whose graphs had poor focus (zoom) or minor problems in the selection of the ROI were graded a 3, four pairs $(15 \%)$ who had major problems in the selection of the plateau were graded a 2 , and three pairs (12\%), which had either not zeroed out the acceleration at the plane, or chosen the point of impact of the body with the base of the inclined plane instead of the area where the acceleration was constant, received a grade of 1 .

\subsection{Step 8: Saving changes}

In this step the students were asked to save the changes they had made during the intervening steps 6 and 7 to the original file they had created during step 5 (so that their choice of the ROI and measured acceleration would also be stored), and then to send this file via email to the researchers. As mentioned previously, the purpose of this step was to provide the researchers with a complete picture of all the data obtained by students during the process of performing the experiment in order to analyze them after the experiment had been completed.

Findings: All 26 pairs received a grade of 4 as both the changes were saved correctly, and the data was sent to the researchers without problems.

\subsection{Step 9: Calculations}

In this last step of the process, the students were asked to use the mean value of the acceleration (from Step 7) as well as the measurement of the angle $\varphi$ (Step 3) to calculate the coefficient of kinetic friction between the body and the inclined plane, using equation (1).

Findings: The students used the calculator of their MP in scientific mode. Although the conversion between rad and degrees of the angle measurement had been explained during the pre-implementation briefing, one team could not perform the specific conversions and was led to miscalculations before being assisted by the researchers (receiving a grade of 2). Also, six pairs (23\%) kept all the decimal places 
both in the calculation of the acceleration and in the calculation of the kinetic friction coefficient (resulting in a grade of 3 ). The remaining $73 \%$ of the pairs completed the operations and calculations without problems (receiving a grade of 4 ).

\section{Discussion-Conclusion}

The aim of the present work is to investigate the difficulties students face when they conduct an experiment with the help of a "smart" mobile device that they bring with them into the laboratory. It is important to note that the students were thoroughly briefed by the researchers before the implementation of the experiment since we considered it necessary to provide detailed instructions and explanations relating to the procedures, at least during the first application of the process in a classroom or in a lab, as students were likely to be unfamiliar with the specific applications.

The data analyzed were the researchers' assessments of students' performance of each step, the final evaluation sheets completed by the researchers who had monitored the pairs of students and, finally the files that the students had emailed to the researchers after the completion of the experiment. Based on these data, each pair was evaluated on the various steps involved in the performance of the experiment, steps which incorporate the ten key points mentioned in the "Implementation and Evaluation" section above.

The analysis shows that the difficulties encountered by the students were mainly in the steps requiring detailed manipulations on the screen of their MPs. Specifically, these steps concerned the selection of an appropriate measurement rate and number of decimal places in the acceleration measurements, as well as the correct selection of the plateau area from the graph and the calculation of the acceleration. However, even in these steps, most groups performed well or with little intervention from the researchers. The steps which students found easier to manage were those of storing data and saving changes, probably because they were familiar with these types of tasks from experience with other applications.

In general, the students did not face any particular difficulties in performing the experiment and, from our first assessment, were probably not presented with greater difficulties than those they would have faced in a classic experiment with school instruments and devices that they had not used before. Of course, this latter conclusion needs further corroboration. However, given that the students performed the experiment using an MP for the first time, we consider it reasonable to speculate that if they had used MP sensors more systematically to take measurements in the school lab the results would have been even better.

As already mentioned, students encountered considerable difficulty in the interpretation of the acceleration time diagram, which required the decisive intervention of the researchers; this particular difficulty was not investigated in depth, as it was not the aim of the present work. However, on first assessment it seems to be related to the students' difficulty in relating the concepts of physics as taught in class to their empirical content. Also, in the case of MPs, the high frequency and accuracy of measurements resulted in details that are not in line with the theoretical model that students 
have learned in class or from textbooks. For example, when the body slides down on the inclined plane there are vibrations, and the kinetic friction coefficient may not be constant; thus, the time acceleration diagram is not a constant function, as predicted by the theoretical model. Therefore, a potential extension of the present research would be to investigate the students' difficulties in interpreting the data, resulting from measurements made with applications that utilize the sensors of "smart" mobile devices.

As the period of quarantine due to the covid-19 pandemic has brought to light, in an environment of distance learning there is also a need for students to engage in experimental work during a science course. The present study showed that a large percentage of students are able to perform experiments in which they take and process measurements using a MP by following the instructions on a worksheet. This gives us a reason to think that with proper preparation, students could perform experiments with simple materials at home, using their MPs to take and process the necessary measurements. Students could then send the results, along with a video of them conducting the experiment, to the teacher for evaluation. This is a research proposal that we are already implementing.

The present paper is a case study involving a particular class of a secondary school; therefore, it has certain limitations and the results cannot be generalized without precautions and further studies. For example, one obvious limitation is that although the research was focused on the ability of students to use the devices in the context of a physics lab, it was not carried out in real laboratory conditions so it was not possible to check whether the teacher could respond to the coordination of a large number of groups. However, the sample of 52 students is large enough to permit us to draw the first conclusions. Thus, it may be worthwhile to repeat the research in a typical school laboratory with all students of a class present in order to determine whether any problems may arise, such as students becoming distracted or the teacher's coordination of a large number of students [9] [27] [29]. Finally, as already mentioned, challenges for future research concern students' ability to perform experiments using MPs and simple materials, as well as student's ability to interpret the graphs depicted on MPs when using appropriate apps to take measurements.

In conclusion, we can support that the results of our study show that the integration of students" "smart" mobile devices in the performance of physics experiments in the classroom or in the school lab is possible and does not present any particular problems. This conclusion is reinforced by the findings of previous research [28], whose results show that the wide variety of students' MPs does not cause problems and does not lead to statistically significant discrepancies in the results of the experiments. However, this integration presupposes the proper planning by the teacher, and the dedication of appropriate time both for the preparation of the students for the activity and for the installation of the necessary applications in the devices. 


\section{$5 \quad$ References}

[1] Keengwe, J., \& Bhargava, M. (2014). Mobile learning and integration of mobile technologies in education. Education and Information Technologies, 19(4):737-746. https://doi. org/10.1007/s10639-013-9250-3

[2] Kukulska-Hulme, A., \& Traxler, J. (2005). Mobile Learning. A handbook for educators and trainers. London: Routledge.

[3] Hwang, G.J., \& Tsai, C. C. (2011). Research trends in mobile and ubiquitous learning: a review of publications in selected journals from 2001 to 2010. British Journal of Educational Technology, 42(4): E65-E70. https://doi.org/10.1111/j.1467-8535.2011.01183.x

[4] Crompton H., Burke, D., Gregory, K.H., \& Gräbe, S. (2016). The Use of Mobile Learning in Science: A Systematic Review. Journal of Science Education and Technology, 25: 149160. https://doi.org/10.1007/s10956-015-9597-x

[5] Crompton, H. (2013). A historical overview of mobile learning toward learner-centered education. In Handbook of mobile learning, edited by Zane L. Berge and Lin Y. Muilenburg, 3-14. New York: Routledge.

[6] Traxler, J. (2009). Learning in a Mobile Age. International Journal of Mobile and Blended Learning, 1(1): 1-12. https://doi.org/10.4018/jmbl.2009010101

[7] Papadakis, S., \& Kalogiannakis, M. (2017). Mobile educational applications for children. What educators and parents need to know. International Journal of Mobile Learning and Organisation, 11(3):256. https://doi.org/10.1504/IJMLO.2017.085338

[8] Papadakis, St. (2020). Robots and Robotics Kits for Early Childhood and First SchoolAge. International Journal of Interactive Mobile Technologies (iJIM), 14 (18), 34-56. https://doi.org/10.3991/ijim.v14i18.16631

[9] Gikas, J., \& Grant, M. M. (2013). Mobile Computing Devices in Higher Education: Student Perspectives on Learning with Cellphones, Smartphones \& Social Media. The Internet and Higher Education, 19:18-26. https://doi.org/10.1016/j.iheduc.2013.06.002

[10] Anshari, M., Almunawar, M. N., Shahrill, M., Wicakson, D. K., \& Huda, M. (2017). Smartphones usage in the classrooms: Learning aid or interefence? Education Information and Technology, 22(6): 3063-3079. https://doi.org/10.1007/s10639-017-9572-7

[11] Georgiev, T., Georgieva, E., \& Smrikarov, A. (2004). M-Learning - a New Stage of ELearning. In Proceedings of the 5th international conference on computer systems and technologies IV28.1-IV28.5. New York: Association for Computing Machinery. https://doi.org/10.1145/1050330.1050437

[12] Kattayat, S., Josey, S., \& Baiju, A. (2017). Mobile Learning Apps in Instruction and Students Achievement. International Journal of Interactive Mobile Technologies (iJIM), 11(1):143. https://doi.org/10.3991/ijim.v11i1.6420

[13] Shi, W. Z., Sun, J., Huan, C., \& Huan, W. (2016). Assessing the Use of Smartphone in the University General Physics Laboratory. EURASIA Journal of Mathematics, Science and Technology Education, 12(1):125-32. https://doi.org/10.12973/eurasia.2016.1424a

[14] Darmaji, D., Kurniawan, D. A., Astalini, A., Lumbantoruan, A., \& Samosir, S. C. (2019). Mobile Learning in Higher Education for the Industrial Revolution 4.0: Perception and Response of Physics Practicum. International Journal of Interactive Mobile Technologies, 13(09):4-20. https://doi.org/10.3991/ijim.v13i09.10948

[15] Sukariasih, L., Sahara, L. Hariroh, L., \& Fayanto, S. (2019). Studies The Use of Smartphone Sensor for Physics Learning. International Journal of Scientific \& Technology Research, 8(10): 862-870. 
[16] Kuhn, J., \& Vogt, P. (2013). Smartphones as Experimental Tools: Different Methods to Determine the Gravitational Acceleration in Classroom Physics by Using Everyday Devices. European Journal of Physics Education, 4(1): 47-58.

[17] Vogt, P., Kuhn, J., \& Neuschwander, D. (2014). Determining ball velocities with smartphones. The Physics Teacher, 52: 376-377. https://doi.org/10.1119/1.4893100

[18] González, M. A., \& González, M. Á. (2018). Smartphones as experimental tools to measure acoustical and mechanical properties of vibrating rods. European Journal of Physics, 37: 1-13. https://doi.org/10.1088/0143-0807/37/4/045701

[19] Klein, P., Hirth, M., Gröber, S., Kuhn, J., \& Müller, A. (2014). Classical experiments revisited: smartphones and tablet PCs as experimental tools in acoustics. Physics Education, 49: 412-418. https://doi.org/10.1088/0031-9120/49/4/412

[20] Silva, M. R., Martin-Ramos, P., \& da Silva, P.P. (2018). Studying cooling curves with a smartphone. The Physics Teacher, 56: 53-56. https://doi.org/10.1119/1.5018696

[21] Kapotis, E., \& Kalkanis, G. (2016). Einstein's Elevator in Class: A Self-Construction by Students for the Study of the Equivalence Principle. The Physics Teacher, Vol. 54: 404407. https://doi.org/10.1119/1.4962774

[22] Menon, D., Chandrasekhar, M., Kosztin, D., \& Steinhoff, D.C. (2019). Impact of mobile technology-based physics curriculum on preservice elementary teachers' technology selfefficacy. Science education, 104 (2): 252-289. https://doi.org/10.1002/sce.21554

[23] Wright, K. (2020). Smartphone Physics on the Rise. APS Physics, April 27. https://physics.aps.org/articles/v13/68

[24] Stavert, B. (2013). BYOD in Schools Literature Review 2013. State of NSW, Department of Education and Communities.

[25] Cochrane, T., Antonczak, L., Keegan, H., \& Narayan, V. (2014). Riding the wave of BYOD: developing a framework for creative pedagogies. Research in Learning Technology, 22. https://doi.org/10.3402/rlt.v22.24637

[26] Mac Callum, K., \& Day, S. (2015). BYOD Perceptions and Reality. Paper presented at the 28h Annual Conference of the National Advisory Committee on Computing Qualifications, Queenstown, New Zealand, October 6-9.

[27] Farley, H., Murphy, A., Johnson, C., Carter, B., Lane, M., Midgley, W., Hafeez-Baig, A., Dekeyser, S., \& Koronios, A. (2015) How do students use their mobile devices to support learning? A case study from an Australian regional university. Journal of Interactive Media in Education, 15 (1):1-13. https://doi.org/10.5334/jime.ar

[28] Kateris, A., Lazos, P., Tsoukos, S., Tzamalis, P., \& Velentzas, A. (2020). Possible Technical Problems Encountered by The Teacher in The Incorporation of Mobile Phone Sensors in The Physics Lab. European Journal of Physics Education, 11 (2): 5-23.

[29] Nikolopoulou, K., \& Kousloglou, M. (2019). Mobile Learning in Science: A Study in Secondary Education in Greece. Creative Education, 10, 1271-1284. https://doi.org/10.4236/ ce.2019.106096

[30] Hochberg, K., Becker, S., Louis, M., Klein, P., \& Kuhn, J. (2020). Using Smartphones as Experimental Tools - a Follow-up: Cognitive Effects by Video Analysis and Reduction of Cognitive Load by Multiple Representations. Journal of Science Education and Technology, 29: 303-317. https://doi.org/10.1007/s10956-020-09816-w

[31] Gonzalez M.A., Martin, M.E., Llamas, C., Martinez, O., Vegas, J., Herguedas, M., Hernandez, C. (2017). Teaching and Learning Physics with Smartphones. In Blended Learning: Concepts, Methodologies, Tools, and Applications. 866-885. DBA Information Resources Management Association, USA. http://dx.doi.org/10.4018/978-1-5225-0783$\underline{3 . \operatorname{ch} 044}$ 
[32] Iliaki G., Velentzas, A., Michailidi, E., \& Stavrou, D. (2019). Exploring the music: a teaching learning sequence about sound in authentic settings. Research in Science \& Technological Education, 37(2): 218-238. https://doi.org/10.1080/02635143.2018.1526170

[33] Martínez, L., \& Garaizar, P. (2014). Learning Physics Down a Slide: A Set of Experiments to Measure Reality Through Smartphone Sensors. International Journal of Interactive Mobile Technologies (iJIM), 8(3):40. http://dx.doi.org/10.3991/ijim.v8i3.3873

\section{Authors}

Serafeim Tsoukos has a PhD in Medical Physics. He is currently teaching physics in the 2nd Experimental Junior High School of Athens, Greece. He is interested in the use of smartphones and technology in physics education.

Panagiotis Lazos is a PhD student in the Faculty of Primary Education of the National and Kapodistrian University of Athens. He is currently the head of the $4^{\text {th }}$ Laboratory Center of Natural Sciences of Athens. His scientific and research interests include the study of the use of smart mobile devices and microcontrollers in physics education, especially in the school science laboratory.

Pavlos Tzamalis has a $\mathrm{PhD}$ in Crystallography. He is currently in the teaching staff of the physics laboratory in the Biotechnology Department of the Agricultural University of Athens. He is interested in the use of technology to enhance learning in physics.

Alexandros Kateris has a $\mathrm{PhD}$ in Medical Physics. He is currently teaching physics in the 2nd Experimental Lyceum of Athens, Greece. He is interested in m-learning especially in physics education.

Athanasios Velentzas has a $\mathrm{PhD}$ in Science Education. He is currently in the teaching staff of the physics department in the School of Applied Mathematical and Physical Sciences of the National Technical University of Athens. His research areas include m-learning, and real/virtual/ thought experiments in physics education.

Article submitted 2021-03-01. Resubmitted 2021-05-05. Final acceptance 2021-05-06. Final version published as submitted by the authors. 